\title{
Effects of polyether siloxane surfactant on the hydrophilic capacity of polypropylene films
}

\author{
Lucas Fiamenghi Antunes $^{1 *}$ (D), Douglas Alexandre Simon ${ }^{1}$, Rudinei Fiorio ${ }^{1}$ and Edson Francisquetti ${ }^{1}$ \\ 'Programa de Pós-graduação em Tecnologia e Engenharia de Materiais - PPGTEM, Instituto Federal do \\ Rio Grande do Sul - IFRS, Farroupilha, RS, Brasil \\ *lucarque@yahoo.com.br
}

\begin{abstract}
To evaluate the hydrophilic capacity, polypropylene and surfactant (polyether siloxane) samples were extruded in the proportions of $0.0,0.5,1.0$ and $3.0(\mathrm{wt} \%)$ and films were obtained in a heated press. The samples were submitted to measurements of contact angle, surface tension, melt flow index and surface roughness. The results indicated that increasing surfactant content promoted better wettability and consequently higher hydrophilicity. Using water, the increase in the surfactant content reduced the contact angle $\left(92.58^{\circ}\right.$ to $\left.68.10^{\circ}\right)$ and increased the surface tension ( 26.7 to $\left.56.9 \mathrm{mN} \cdot \mathrm{m}^{-1}\right)$. However, with ethylene glycol, increasing the surfactant content promoted a small variation on the contact angle $\left(59.14^{\circ}\right.$ to $\left.65.10^{\circ}\right)$ and on the surface tension $\left(5.5\right.$ to $\left.5.0 \mathrm{mN} \cdot \mathrm{m}^{-1}\right)$. The surfactant promoted a slight change in the melt flow index but not affected the roughness of the samples.
\end{abstract}

Keywords: hydrophilicity, polyether siloxane, polypropylene, wettability.

How to cite: Antunes, L. F., Simon, D. A., Fiorio, R., \& Francisquetti, E. (2019). Effects of polyether siloxane surfactant on the hydrophilic capacity of polypropylene films. Polimeros: Ciência e Tecnologia, 29(4), e2019048. https://doi. org/10.1590/0104-1428.06518

\section{Introduction}

Polypropylene (PP) is currently one of the most studied polymers, mainly because of its interesting properties as moderate rigidity above glass transition temperature, relatively high melting point (allowing its use at temperatures higher than $100^{\circ} \mathrm{C}$ ), low density, hydrophobic characteristics, diversity in mechanical properties, low cost and high availability ${ }^{[1,2]}$.

PP can also be used for the manufacture of non-woven products, which are widely used in filtration processes, agriculture, hygiene products, protective clothing and also for the production of carpets ${ }^{[3]}$. The manufacture of non-woven products usually occurs through melt-blown or spunbond processes. The most common process is melt blown, which is an extrusion process in which the molten polymer passes through air jets after exiting the extrusion die, causing the diameter of the fiber to decrease when in contact with ambient air, forming a web ${ }^{[4]}$.

Due to the wide range of non-woven applications, sometimes it is necessary to modify the characteristics of the resin from hydrophobic to hydrophilic in order to provide adsorption ability for certain fluids ${ }^{[2]}$. Several studies have been carried out to investigate this modification; the contact angle measurement is usually an indicative of wettability (hydrophilicity). The tendency of a liquid to spread or wet the surface of a solid increases as the contact angle decreases. Thus, the contact angle represents an inverse measurement of wettability ${ }^{[5]}$.

When the contact angle $(\theta)$ is lower than $90^{\circ}$, the surface can be characterized as hydrophilic (considering water as

the liquid). When the angle is between $90^{\circ}$ and $180^{\circ}$, it can be said that the surface is hydrophobic, being called predominantly non-wetting ${ }^{[6]}$. Andersen and Taboryski ${ }^{[7]}$, after several analyses of the drops shapes, traced a drops profile as shown in Figure 1.

The modification of the hydrophobic to hydrophilic capacity of the non-woven PP is commercially important, considering the applications for automotive components, such as: benches, internal part of doors, for the protection of the instruments of dashboards, aiming the replacement of the natural fibers, which degrade in a short period of time $^{[8]}$. However, for the utilization of non-woven PP in substitution of natural fibers, the PP needs an industrially and economically viable modification.

Wang et al. ${ }^{[9]}$ investigated the improvement of the hydrophilic properties of the non-woven surface of polypropylene using a plasma atmosphere by dielectric barrier discharge in nitrogen at atmospheric pressure. The authors characterized the samples by contact angle measurements, scanning electron microscopy (SEM) and Fourier transform infrared spectroscopy (FTIR), before and after the plasma treatment. Their results showed that the surface of the samples presented hydrophilic properties after the plasma treatment, evidenced by the reduction of the contact angle; the plasma treatment also promoted an increase in the surface roughness and the introduction of oxigen- and nitrogen-containing polar groups on the surface of PP. 
(1)

Very Hydrophilic

Flat
(2)

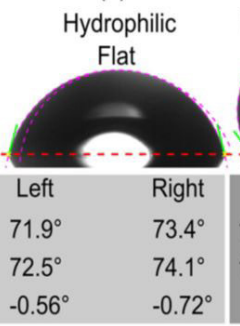

(3)

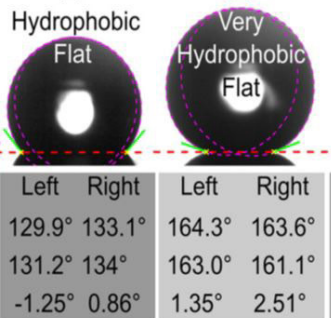

(5)

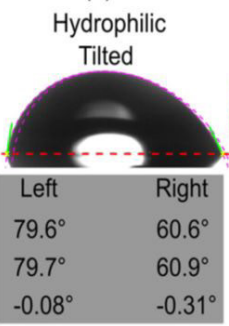

(6)

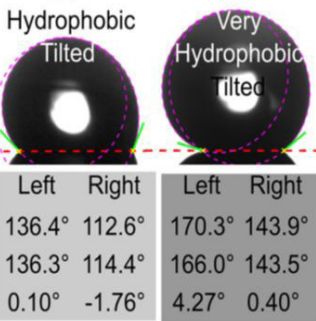

Figure 1. Drops profile (1), (2), (5): $\theta<90^{\circ}=$ hydrophilic; (3), (4), (6), (7): $\theta>90^{\circ}=$ hydrophobic.

In order to modify the wettability of PP, Wanke et al. ${ }^{[10]}$ compared the plasma surface treatment with the ultraviolet vacuum technique (VUV) aiming to introduce functional groups containing oxygen in the material. The samples were analyzed by FTIR, atomic force microscopy (AFM) and contact angle with the objective of evaluating the chemical and physical changes of the PP surface. The authors observed that plasma treated samples presented better efficiency when compared to those treated by VUV; the plasma treated samples required a shorter exposure time to obtain the same contact angle. The chemical modification that occurred in both processes was observed after a 14-day exposure to plasma and ultraviolet light, which was measured by FTIR. The AFM analysis did not show change in the roughness of the samples after the exposure period.

Zhang, Sun and Xiao ${ }^{[11]}$ studied the effects of the wettability of 16 additives introduced into the non-woven fibers produced by the melt-blown process. The effect of the additives on the surface tension of the polymers was determined by the measurement of the contact angle, and also the interference of the additive in the melt viscosity. The additives were divided into five groups according to their chemical functionality; the additive that presented the best performance reducing the surface tension was a surfactant of the family of the polyethers modified with trisiloxane.

The aim of this study was to investigate and evaluate the effect of the addition of polyether siloxane in a polypropylene film in order to increase the hydrophilic characteristics, allowing the sorption of polar materials, such as water.

\section{Materials and Methods}

\subsection{Materials}

The polypropylene (PP, H107, Braskem) used was a homopolymer, whose density is $905 \mathrm{~kg} / \mathrm{m}^{3}$ and the melt flow index (MFI) is $80 \mathrm{~g} / 10 \mathrm{~min}\left(230^{\circ} \mathrm{C} / 2.16 \mathrm{~kg}\right)$. The surfactant used corresponds to a polyether siloxane (Tegopren 5840, Evonik), nonionic, liquid material.

\subsection{Sample Preparation}

The compounds studied contained $0,0.5,1.0$ and $3.0 \mathrm{wt} \%$ of surfactant, according to Table 1. Before the extrusion process, PP granules and the surfactant used (a liquid at room temperature) were manually mixed for 5 minutes. After the manual mixing, the samples remained at rest for seven days. After this period the samples were extruded in
Table 1. PP Samples + Surfactant.

\begin{tabular}{lcccc}
\hline \multicolumn{5}{c}{ Sample } \\
\multicolumn{1}{c}{ Product } & $\mathbf{1}$ & $\mathbf{2}$ & $\mathbf{3}$ & $\mathbf{4}$ \\
\hline Quantity surfactant (\%) & 0.0 & 0.50 & 1.0 & 3.0 \\
Surfactant mass (g) & 0 & 10 & 20 & 60 \\
PP mass (g) & 2000 & 1990 & 1980 & 1940 \\
\hline
\end{tabular}

a twin-screw co-rotating extruder (MScientific, Lab Tech Engineering Company), with mass temperature of $195^{\circ} \mathrm{C}$ and screw rotation of $220 \mathrm{rpm}$, obtaining pellets from which four films were produced in a heated press $\left(210^{\circ} \mathrm{C}\right.$, 29.4 MPa, 4 minutes). The test specimens were obtained from these films.

\subsection{Characterization}

\subsubsection{Contact angle measurements}

To measure the contact angles, deionized water, ethylene glycol, a high definition photographic camera and the software Surftens 4.7 were used.

The method used to perform the contact angle measurements was the "sessile drop". This method consists of depositing a drop of a liquid on a solid surface; the droplet is magnified with a lens, and the contact angle is measured by the principle of the goniometer. The contact angle was defined as the angle between the tangent of liquid interface - air and the tangent between the solid interface - air, as shown in Figure 2.

For each sample, 6 measurements of the contact angle were made and the average of these measurements was used to express the result.

\subsubsection{Surface tension}

The surface tension was obtained by using Young's method, considering that the drop is in equilibrium, applying Young's Equation $1^{[12]}$.

$$
\gamma S V=\gamma S L+\gamma L V \cdot \cos \theta
$$

- $\theta$ : drop contact angle;

- $\gamma \mathrm{SV}$ : surface tension of the solid vapor;

- $\gamma \mathrm{LV}$ : surface tension liquid vapor;

- $\gamma \mathrm{SL}$ : surface tension of solid liquid. 
Table 2 shows the values of $\gamma \mathrm{LV}$ and $\gamma \mathrm{SV}$ under the normal conditions of temperature and pressure. The $\gamma \mathrm{SL}$ value was obtained experimentally through the measurement of the contact angle.

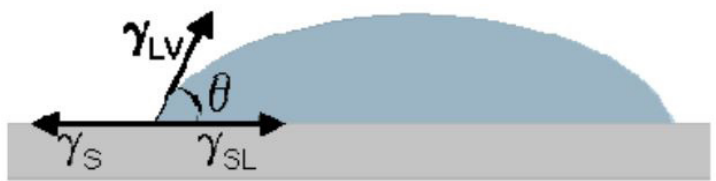

Figure 2. Contact angle setting.

Table 2. Tabulated Values $\gamma \mathrm{LV}$ e $\gamma \mathrm{SV}$.

\begin{tabular}{lccc}
\hline \multicolumn{1}{c}{ Sample } & $\gamma \mathbf{L V}\left(\mathbf{m N} \cdot \mathbf{m}^{-\mathbf{1}}\right)$ & $\boldsymbol{\gamma} \mathbf{S V}\left(\mathbf{m N} \cdot \mathbf{m}^{-\mathbf{1}}\right)$ & Reference \\
\hline Deionized Water & 72.8 & ------- & ${ }^{[13]}$ \\
Ethylene Glycol & 47.7 & ------ & ${ }^{[14]}$ \\
Pure PP & ------ & 30.7 & ${ }^{[15]}$ \\
\hline
\end{tabular}

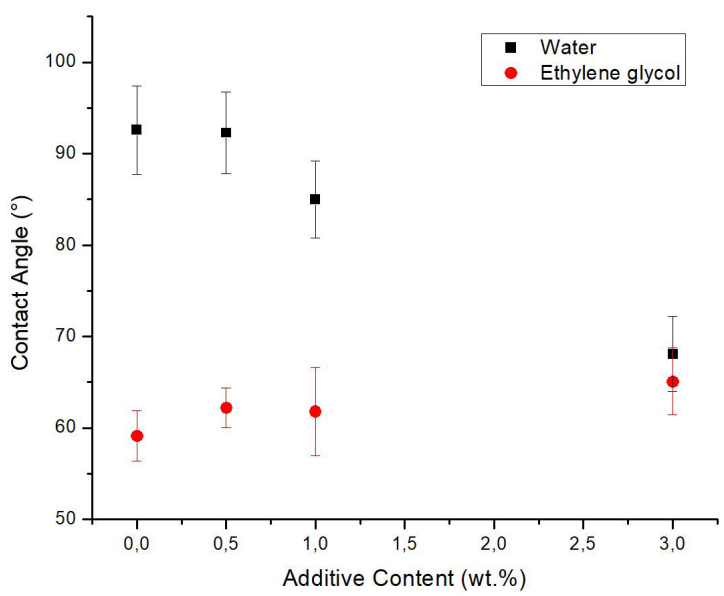

Figure 3. Contact angle in PP films with different surfactant concentrations.

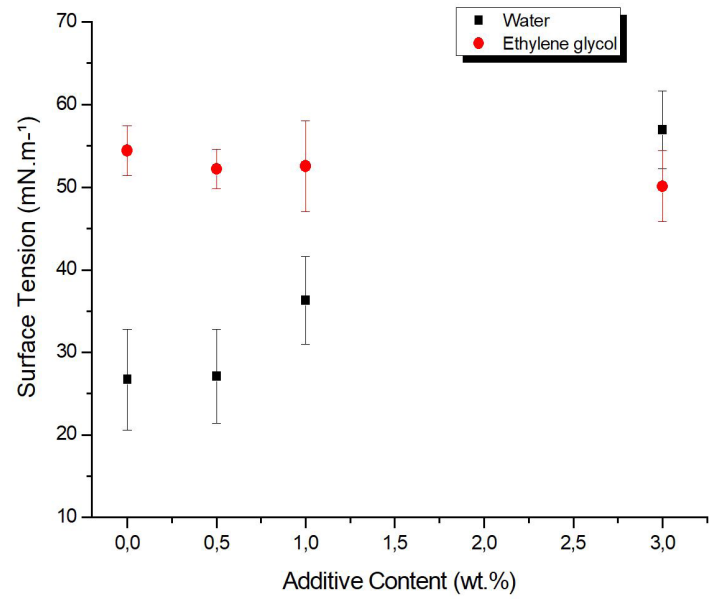

Figure 4. Surface Tension in PP films with different surfactant concentrations.

\subsubsection{Roughness}

The surface roughness was determined by the standard NBR ISO $4287^{[16]}$. The values were obtained from the arithmetic average of 6 measurements for each sample, using a TR110 surface roughness tester. The method used was the roughness average $(\mathrm{Ra})$ that is obtained from the arithmetic average of the absolute values of the ordinates of the spacings of the roughness profile points, in relation to the medium line, within the measurement path, which in this case was $2 \mathrm{~cm}^{2}$.

\subsubsection{Melt Flow Index (MFI)}

The melt flow index (MFI) was measured at $230^{\circ} \mathrm{C}$ and $2.16 \mathrm{~kg}$ on an Instron plastomer according to the standard ASTM D1238 ${ }^{[17]}$. The average results were obtained from 10 measurements with the objective of evaluating the influence of the surfactant on the fluidity of the compound and consequently associated with possible effects in the processing.

\section{Results and Discussions}

\subsection{Contact angle}

The contact angle measurement was used to determine the hydrophobic/hydrophilic character of the polypropylene using deionized water and ethylene glycol. In this study an average contact angle of $92.58^{\circ}$ was obtained for the unmodified PP in water. A similar result was found by Brow and Bhushan ${ }^{[13]}$ who obtained a measure of $96^{\circ}$ using water and PP.

Figure 3 shows the average contact angle values obtained for each sample. For the deionized water, it was observed that the addition of the surfactant reduces the contact angle value. However, for the ethylene glycol, an increasing trend for the contact angle was observed with the increase in the surfactant content. This difference is related to the higher hydrophilic character of the water compared to the ethylene glycol. For the water, the lower contact angle result was obtained with the addition of $3.0 \mathrm{wt} \%$ of surfactant. A similar behavior was also observed by Zhang, Sun and $\mathrm{Xiao}^{[11]}$ with deionized water. The contact angle change in ethylene glycol shows changes in the apolar component influenced by the surfactant characteristics (polyether siloxane). Wang, Bratko and Luzar ${ }^{[18]}$ studied the contact angle variation in a natural (protein-based) and a synthetic (graphene layers functionalized with polar and apolar groups) surface. These authors observed that, along the surface, the angle varied according to the influence of neighboring groups. The influence of the polar (hydroxyl) and apolar (ethylene) segments of the ethylene glycol, as well as the chemical groups present in the surfactant (ether, methyl, and siloxane), can have the same effect.

\subsection{Surface tension}

Figure 4 shows the averages obtained from surface tension (solid/liquid) for water and ethylene glycol. It is observed that a variation of the surface tension occurs as the concentrations of the surfactant are increased, possibly due to the fact that the surfactant is migrating to the surface of the samples, increasing the concentration of siloxane 


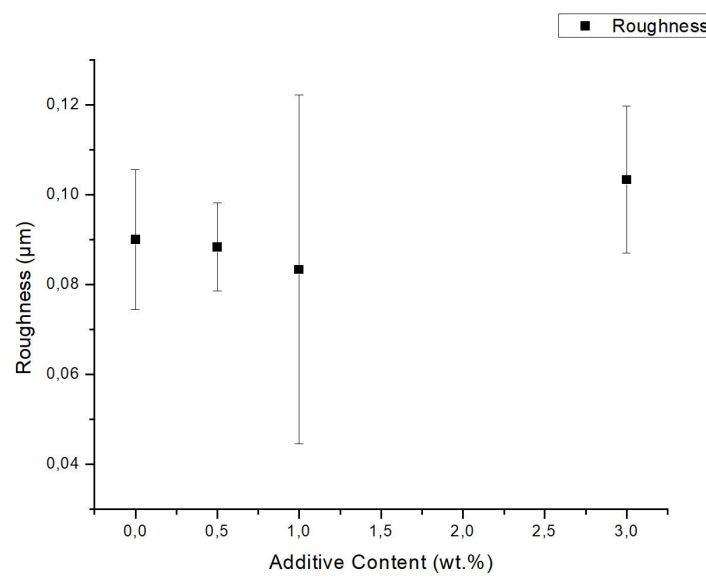

Figure 5. Roughness in PP films with different surfactant concentrations.

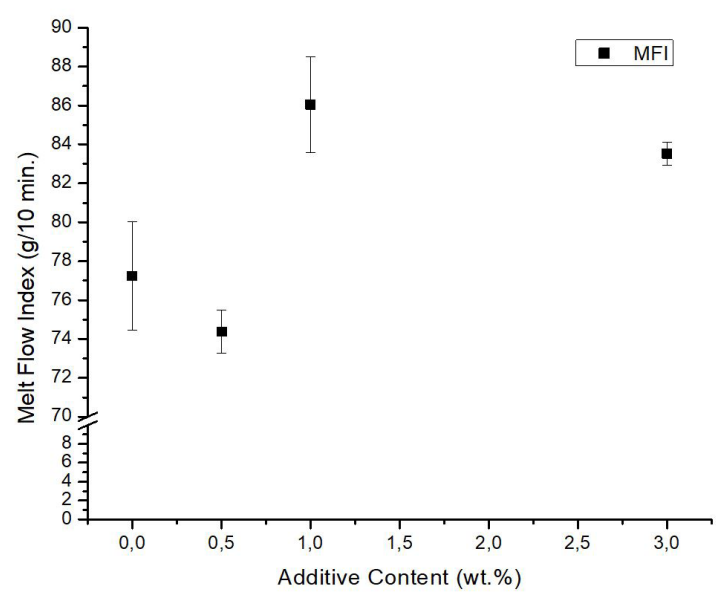

Figure 6. MFI in PP films with different surfactant concentrations.

molecules on the PP surface. This migration can increase the hydrophilicity and the surface tension. Farris et al. ${ }^{[19]}$ studied some features to improve the wettability and adhesion properties of polyolefin surfaces, proven through the reduction of the contact angle and consequently for the increase of the surface tension, which changed the shape of the drop from spherical to laminate. Similar behaviours are verified in Figures 3 and 4 for water where the decrease of the contact angle and the incresase of surface tension occurs. However, in ethylene glycol, the increase trend for the surface tension is possibly associated with an interaction with neighboring groups (methyl and ethers), as described by Wang, Bratko and Luzar ${ }^{[18]}$.

Zhang, et al. ${ }^{[11]}$ observed a variation of the surface tension when adding a polyether to the PP, and associated this change to a possible migration of the polyether from the solid interior to the surface of PP, thus increasing the PP hydrophilicity.

\subsection{Roughness}

Figure 5 shows the average of the surface roughness obtained for the samples. It was observed that there was no significant variation among the roughness of the studied samples. Therefore, the contact angle variation observed was mainly related to the surfactant content. Grundke et al. ${ }^{[20]}$ highlighted that the study of the relation between contact angle and roughness has increased greatly in the last decades, especially studying wettability as a factor for self-cleaning products. They proved that increasing the surface roughness causes variations in the contact angle measurement in the range of $40^{\circ}$.

The relation between contact angle and roughness was studied by Morrow ${ }^{[2]}$ which indicates that the preparation of a smooth solid surface is recognized as an important factor in obtaining reproducible results. In this work, it was not possible to observe a significant variation for the roughness, indicating that the surfactant promoted the modification of the contact angle values.

\subsection{Melt Flow Index (MFI)}

Figure 6 shows the melt flow index results for the studied samples. From Figure 6, it is observed that the addition of surfactant in concentrations of 1.0 and $3.0 \mathrm{wt} \%$ induced to a slight increase in the MFI. This was expected due to a lubricant effect of the surfactant.

\section{Conclusions}

The addition of the polyether siloxane provided a variation in the hydrophilic capacity of the polypropylene, where an addition of $3.0 \mathrm{wt} \%$ of surfactant promoted the highest increase in the hydrophilicity, substantially reducing the contact angle when deionized water was used. When ethylene glycol was used, no significant variation of the contact angle was observed.

The surface tension variation suggests that the surfactant can migrate to the surface of the polypropylene film, increasing the wettability and consequently promoting a reduction in the contact angle value.

The modification of the contact angle was not influenced by the roughness, since all the samples presented similar roughness.

Increasing the surfactant content did not cause a large modification on the MFI values.

\section{References}

1. Spadetti, C., Alves da Silva Filho, E., Lopes de Sena, G., \& Vital Paixão de Melo, C. (2017). Propriedades térmicas e mecânicas dos compósitos de Polipropileno pós-consumo reforçados com fibras de celulose. Polímeros: Ciência e Tecnologia, 27(número especial), 84-90. https://orcid.org/10.1590/0104-1428.2320.

2. Hutten, I. M. (2016). Handbook of nonwoven filter media. Delray Beach: Elsevier Ltd.

3. Soltani, I., \& Macosko, C. W. (2018). Influence of rheology and surface properties on morphology of nanofibers derived from islands - in-the-sea meltblown nonwovens. Polymer, 145, 21-30. http://dx.doi.org/10.1016/j.polymer.2018.04.051.

4. Zhang, H., Liu, J., Zhang, X., Huang, C., \& Jin, X. Online prediction of the filtration performance of polypropylene melt blown nonwovens by blue-colored glow. Journal of Applied Polymer Science [Internet]. 2017[cited 2019, October 26];135(10):1307. Available from: https://onlinelibrary.wiley. com/doi/epdf/10.1002/app.45948 
5. Chan, C. M. (1994). Polymer surface modification and characterization. Munich: Hanser/Gardner Publications.

6. Lamour, G., Hamraoui, A., Buvailo, A., Xing, Y., Keuleyan, S., Prakash, V., Bafrooei, A. E., \& Borguet, E. (2010). Contact angle measurements using a simplified experimental setup. Journal of Chemical Education, 87(12), 1403-07. http://dx.doi. org/10.1021/ed100468u.

7. Andersen, N. K., \& Taboryski, R. (2017). Drop shape analysis for determination of dynamic contact angles by double sided elliptical fitting method. Measurement Science \& Technology, 28(4), 047003. http://dx.doi.org/10.1088/1361-6501/aa5dcf.

8. Sullins, T., Pillay, S., Komus, A., \& Ning, H. (2017). Hemp fiber reinforced polypropylene composites: the effects of material treatments. Composites. Part B, Engineering, 114, 15-22. http://dx.doi.org/10.1016/j.compositesb.2017.02.001.

9. Wang, K., Wang, W., Yang, D., Huo, Y., \& Wang, D. (2010). Surface modification of polypropylene non-woven fabric using atmospheric nitrogen dielectric barrier discharge plasma. Applied Surface Science, 256(22), 6859-64. http://dx.doi. org/10.1016/j.apsusc.2010.04.101.

10. Wanke, C. H., Barbosa, L. G., Hübner, J. V. M., Horowitz, F., Mauler, R. S., \& Oliveira, R. V. B. D. (2012). Recuperação hidrofóbica de polipropileno tratado por VUV ou plasma. Polímeros, 22(2), 158-63. http://dx.doi.org/10.1590/S010414282012005000027.

11. Zhang, D., Sun, C., \& Xiao, J. (2006). Effect of selected additives on surface energy of fibers and meltblown nonwovens. Textile Research Journal, 76(3), 261-65. http:// dx.doi.org/10.1177/0040517506053905.

12. Kan, M., Kawsaki, H., \& Suzumura, F. (2017). A wettability evaluation on super-hydrophobic and hydrophobic surface. In The 4th International Conference on Design Engineering and Science. Aachen, Germany: ICDES. Retrieved from http:// www.jsde.or.jp/icdes/proceedings/4th-2017/PDF/162.pdf

13. Brown, P. S., \& Bhushan, B. (2017). Liquid-impregnated porous polypropylene surfaces for liquid repellency. Journal of Colloid and Interface Science, 487, 437-443. http://dx.doi. org/10.1016/j.jcis.2016.10.079. PMid:27814555.
14. Dean, J. A. (1999). Lange's handbook of chemistry. Knoxville: McGraw-Hill, Inc.

15. Ryntz, R. A., \& Yaneff, P. V. (2003). Coating of polymers and plastics. New York: Marcel Dekker. http://dx.doi. org/10.1201/9780203912379.

16. Associação Brasileira de Normas Técnicas - ABNT. (2002). ABNT NBR ISO 4287: Especificações geométricas do produto (GPS). Rugosidade: método do perfil: termos, definições e parâmetros da rugosidade. Rio de Janeiro: ABNT.

17. American Society for Testing and Materials-ASTM. (2004). ASTM D1238-04: Standard test method for melt flow rates of thermoplastics by extrusion plastometer. West Conshohocken: ASTM.

18. Wang, J., Bratko, D., \& Luzar, A. (2011). Probing surface tension additivity on chemically heterogeneous surfaces by a molecular approach. Proceedings of the National Academy of Sciences of the United States of America, 108(16), 6374-6379. http://dx.doi.org/10.1073/pnas.1014970108. PMid:21460249.

19. Farris, S., Pozzoli, S., Biagioni, P., Duó, L., Mancinelli, S., \& Piergiovanni, L. (2010). The fundamentals of flame treatment for the surface activation of polyolefin polymers - A review. Polymer, 51(16), 3591-3605. http://dx.doi.org/10.1016/j. polymer.2010.05.036.

20. Grundke, K., Pöschel, K., Synytska, A., Frenzel, R., Drechsler, A., Nitschke, M., Cordeiro, A. L., Uhlmann, P., \& Welzel, P. B. (2015). Experimental studies of contact angle hysteresis phenomena on polymer surfaces: toward the understanding and control of wettability for different applications. Advances in Colloid and Interface Science, 222, 350-376. http://dx.doi. org/10.1016/j.cis.2014.10.012. PMid:25488284.

21. Morrow, N. R. (1975). The effects of surface roughness on contact: Angle with special reference to petroleum recovery. Journal of Canadian Petroleum Technology, 14(04), 42-53. http://dx.doi.org/10.2118/75-04-04.

Received: Sept. 21, 2018

Revised: Oct. 26, 2019

Accepted: Nov. 27, 2019 